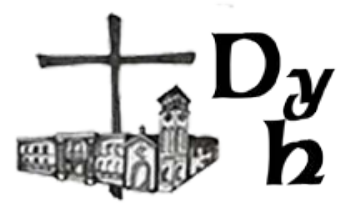

\title{
LA ECOLOGÍA EN EL MAGISTERIO DE LA IGLESIA
}

\author{
Ecology in the Magisterium of the Church \\ Prof. Ezequiel Piro \\ zekepiro@hotmail.com \\ Universidad Católica de La Plata - Buenos Aires - Argentina
}

\begin{abstract}
Resumen
La importancia que ha adquirido en los últimos años la problemática del medio ambiente no quedó al margen del interés de la Iglesia. Desde las primeras manifestaciones implícitas hasta las más explícitas de los últimos años, culminando en la Encíclica Laudato si del Papa Francisco, realizamos un breve recorrido por los puntos más significativos de la enseñanza del Magisterio de la Iglesia.
\end{abstract}

Palabras clave: ecología, medioambiente, Magisterio de la Iglesia, planeta tierra, progreso, consumismo

\begin{abstract}
The importance that has acquired in recent years the issue of the environment was not apart from the interest of the Church. From the earliest implicit manifestations up to the more explicit in recent years, culminating in the Encyclical Laudatosi's Pope Francis, we performed a brief tour of the most significant points in the teaching of the Magisterium of the Church.
\end{abstract}

Keywords: Ecology, Environment, Magisterium of the Church, Earth, Progress, Consumerism 


\section{Introducción}

El interés suscitado desde hace ya algunos años por las cuestiones relacionadas con el medio ambiente no ha sido ajeno a las preocupaciones de la Iglesia. Así se deja ver en la creciente cantidad de páginas destinadas a tal fin que pueden leerse en los distintos documentos eclesiales y discursos de los Sumos Pontífices, conferencias episcopales y obispos de los más variados rincones del mundo.

No decimos nada nuevo cuando afirmamos que el problema surge a partir de la cada vez mayor separación entre la ciencia y la técnica, por un lado y la ética, por el otro. La técnica siempre había sido un medio, un instrumento al servicio del hombre pero desde hace décadas se ha convertido en un fin en sí misma. Es el hombre quien va detrás de ella.

Ahora bien, qué es lo que ha expresado la Iglesia sobre la ecología es lo que intentaremos desarrollar a lo largo de este texto.

El Papa Juan XXIII en su encíclica Mater et Magistraafirma, en relación a la cuestión del incremento demográfico y desarrollo económico que Dios "ha otorgado a la naturaleza una capacidad casi inagotable de producción y ha enriquecido al hombre con una inteligencia tan penetrante que le permite utilizar los instrumentos idóneos para poner todos los recursos naturales al servicio de las necesidades y del provecho de su vida"(Juan XXIII, 1961, n 189).Se observa una mirada llena de esperanza en las posibilidades del hombre pero no exenta de prudencia, pues a la vez advierte que "la solución clara de este problema no ha de buscarse fuera del orden moral establecido por Dios..."(Juan XXIII, 1961, n¹89). Aun cuando la referencia directa tiene que ver con las cuestiones relacionadas con el control demográfico, se puede extrapolar a otros campos ya que "debe procurar el hombre, con toda clase de procedimientos técnicos y científicos, el conocimiento profundo y el dominio creciente de las energías de la naturaleza"(Juan XXIII, 1961, n¹89).

La indicación del Santo Padre de no buscar soluciones fuera del orden moral hay que encuadrarla dentro del mandato bíblico del Génesis. Allí leemos que Dios se dirige al hombre y a la mujer, es decir, a toda la humanidad representada por Adán y Eva en los siguientes términos: "Y los bendijo, diciéndoles: «Sean fecundos, multiplíquense, llenen la tierra y sométanla; 


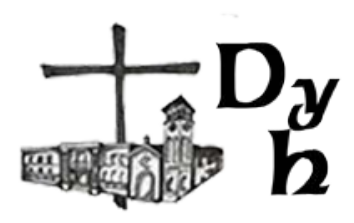

dominen a los peces del mar, a las aves del cielo y a todos los vivientes que se mueven sobre la tierra». Y continuó diciendo: "Yo les doy todas las plantas que producen semilla sobre la tierra, y todos los árboles que dan frutos con semilla: ellos les servirán de alimento»" (Génesis, 1, 28-29).

El Concilio Vaticano II no hace referencia expresa a la cuestión medioambiental pero recuerda algunas ideas fundamentales para pensar el tema. En la Constitución Dogmática sobre la Iglesia Lumen Gentium se lee que "deben... los fieles conocer la íntima naturaleza de todas las criaturas, su valor y su ordenación a la gloria de Dios"(Concilio Vaticano II, 1964, n³6).

En tanto en la Constitución Pastoral Gaudim et spes sobre la Iglesia en el mundo actual se recuerda que el hombre, como dice el libro del Génesis, fue creado a imagen de Dios y que recibió el mandato de "gobernar el mundo en justicia y santidad, sometiendo a sí la tierra y cuanto en ella se contiene, y de orientar a Dios la propia persona y el universo entero"(Concilio Vaticano II, 1965, $\mathrm{n}^{\circ}$ 34). Dicho sometimiento del mundo por parte del hombre debe hacerse bajo el reconocimiento de "Dios como Creador de todo"para que así "sea admirable el nombre de Dios en el mundo"(Concilio Vaticano II, 1965, n³4). Es decir que, según una interpretación adecuada del texto del Génesis, no hay lugar ni justificación para el abuso.

Más adelante refuerza la idea al afirmar que "cuanto más se acrecienta el poder del hombre, más amplia es su responsabilidad individual y colectiva. De donde se sigue que el mensaje cristiano no aparta a los hombres de la edificación del mundo si los lleva a despreocuparse del bien ajeno, sino que, al contrario, les impone como deber el hacerlo"(Concilio Vaticano II, 1965, n³4).

Al mismo tiempo, el documento hace un llamado de atención respecto del progreso, ya que si bien es "altamente beneficioso para el hombre también encierra, sin embargo, gran tentación, pues los individuos y las colectividades, subvertida la jerarquía de los valores y mezclado el bien con el mal, no miran más que a lo suyo, olvidando lo ajeno"(Concilio Vaticano II, 1965, n³7).Lo que se observa es que la codicia desmedida de algunos, de los más poderosos, pone en riesgo la calidad de vida e incluso la vida misma de casi todos seres humanos. 


\section{El Magisterio post-conciliar}

Es a partir de la década de 1970 cuando la cuestión ambiental comienza a volverse un tema central ya que se toma conciencia de la necesidad de realizar acciones concretas destinadas a conservar la habitabilidad en el planeta.

El 16 de noviembre de 1970, el Papa Pablo VI, en el discurso por el $25^{\circ}$ aniversario de la Organización Mundial para la Alimentación y la Agricultura de las Naciones Unidas, hace un Ilamado de atención sobre el peligro que implica el acelerado avance tecnológico para la conservación de la vida sobre el planeta.

Luego de reconocer los aspectos positivos de dicho progreso afirma:

Pero la puesta en marcha de estas posibilidades técnicas a un ritmo acelerado no se realiza sin repercutir peligrosamente en el equilibrio de nuestro medio natural, y el deterioro progresivo de lo que se ha convenido en llamar ambiente natural amenaza conducir a una verdadera catástrofe ecológica bajo el efecto de la explosión de la civilización industrial. Nos estamos viendo ya viciarse el aire que respiramos, degradarse el agua que bebemos, contaminarse los ríos, los lagos, y también los océanos hasta hacer temer una verdadera "muerte biológica" en un futuro próximo, si no se toman pronto enérgicas medidas, valientemente adoptadas y severamente ejecutadas (Pablo VI, 1970).

Menos de un año más tarde, en su carta apostólica Octogesimaadveniens, conmemorativa por el $80^{\circ}$ aniversario de la encíclica Rerumnovarum, el Sumo Pontífice enmarca antropológicamente la situación descrita ante la FAO, al enfatizar que:

No sólo el ambiente físico constituye una amenaza permanente: contaminaciones y desechos, nuevas enfermedades, poder destructor absoluto; es el propio consorcio humano el que la persona no domina ya, creando de esta manera para el mañana un ambiente que podría resultarle intolerable. Problema social de envergadura que incumbe a la familia humana toda entera(Pablo VI, $\left.1971, n^{\circ} 21\right)$.

Los llamados de atención del Santo Padre se suceden. En 1972, durante la Conferencia de las Naciones Unidas sobre el medio ambiente reconoce el surgimiento de una conciencia de lo inseparable que son el hombre y su ambiente natural y de cómo éste condiciona al hombre y, a su vez, el hombre 


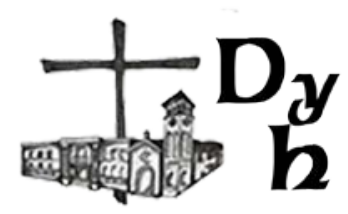

perfecciona al medio ambiente. Pero asegura que "hay que llamar la atención de la humanidad para que sustituya el ímpetu, con mucha frecuencia ciego y brutal, de un progreso abandonado a su único dinamismo, por el respeto a la biosfera" (Pablo VI, 1972).

El Papa sostiene que se deben dejar de lado los objetivos parciales e inmediatos y trabajar para ofrecer a los futuros seres humanos "una tierra que les resulte hospitalaria" (Pablo VI, 1972), pero para que eso sea posible no hay que "afrontar el problema del medio ambiente con las solas medidas de orden técnico" (Pablo VI, 1972), porque aunque estas sean indispensables, no serían suficientes si no estuvieran acompañadas de un cambio de mentalidad de todos los seres humanos.

En 1979, Juan Pablo II reclama que el progreso de la técnica que va marcando el desarrollo del mundo tenga un desarrollo proporcionado en el plano de la moral y de la ética. Por eso se pregunta "¿este progreso, cuyo autor y fautor es el hombre, hace la vida del hombre sobre la tierra, en todos sus aspectos, «más humana»? ¿La hace «más digna del hombre»?"(Juan Pablo II, 1979, $\left.n^{\circ} 8\right)$.

En esta misma línea de pensamiento el Santo Padre expresa la necesidad de hacer una "radiografía" de las distintas etapas del progreso actual para no perder de vista que "se trata del desarrollo de las personas y no solamente de la multiplicación de las cosas, de las que los hombres pueden servirse"(Juan Pablo II, 1979, $\left.\mathrm{n}^{\circ} 16\right)$.

En el año 1987, San Juan Pablo II da la carta encíclica Sollicitudoreisocialis con ocasión del vigésimo aniversario de la encíclica Populorumprogressio, acerca de la preocupación social de la Iglesia. En ella hace referencia a "lo que se llama preocupación ecológica"(Juan Pablo II, 1987, $\mathrm{n}^{\circ}$ 26) como una de las señales positivas de la época, que empieza a tomar conciencia de lo limitados que son los recursos naturales y de la importancia de tener en cuenta la integridad de la naturaleza y sus ritmos para llevar adelante un verdadero desarrollo. Éste supone tres consideraciones imposibles de soslayar: no se pueden utilizar a los seres vivos o inertes solo según el propio beneficio económico; no se pueden usar los recursos naturales como si fueran inagotables; y no se pueden obviar las consecuencias que la industrialización directa o indirectamente trae sobre el ambiente y las personas. 
Al conmemorar los cien años de la encíclica Rerumnovarum, el Sumo Pontífice da a conocer la encíclica Centesimusannus en la que manifiesta su preocupación ya que se dan asociados el problema del consumismo y la cuestión ecológica. En ese marco recuerda que "el hombre, impulsado por el deseo de tener y gozar, más que de ser y de crecer, consume de manera excesiva y desordenada los recursos de la tierra y su misma vida"(Juan Pablo II, 1991, n³7). Todo esto tiene sus raíces en un error antropológico por el cual el hombre, en lugar de colaborar con Dios en la obra creadora, ocupa su lugar y así "provoca la rebelión de la naturaleza, más bien tiranizada que gobernada por él"(Juan Pablo II, 1991, n³7).

El Papa reflexiona acerca de la actitud humana, muy valorable, de preocupación por la conservación de los hábitats naturales de las especies que corren peligro de extinción. Incluso destaca la relación entre dicho cuidado y el "equilibrio general de la tierra"pero a la vez advierte que "nos esforzamos muy poco por salvaguardar las condiciones morales de una auténtica «ecología humana»"(Juan Pablo II, 1991, n³8).

En la misma línea de pensamiento, advierte también acerca de los graves inconvenientes que ha generado la urbanización cuando se separa de la preocupación por la vida de las personas, y reclama, al mismo tiempo, prestar atención "a una «ecología social» del trabajo"(Juan Pablo II, 1991, n 38).

Muy interesante es el Mensaje de Su Santidad para la celebración de la XXIII Jornada Mundial de la Paz del 1 de enero de 1990. Allí hace referencia a que la carrera armamentista, los conflictos y las injusticias del momento -las mismas que ahora, casi 30 años más tarde- profundizan la "sensación de inestabilidad e inseguridad que a su vez favorece formas de egoísmo colectivo, acaparamiento y prevaricación"(Juan Pablo II, 1990, n²1).Remarca que hay en la humanidad una toma de conciencia acerca del inconveniente de continuar usando lo bienes de la tierra como se ha venido haciendo hasta el momento. $Y$ destaca que hay no pocos valores éticos fundamentales que están íntimamente relacionados con la cuestión ambiental. Esto y la interdependencia de muchos de los temas y retos que el mundo debe enfrentar traen aparejada la necesidad de acciones coordinadas que tengan como fundamento "una coherente visión moral del mundo"(Juan Pablo II, 1990, n²). 


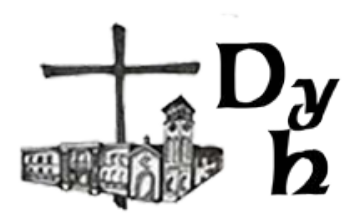

Justamente, en esta línea, el Papa advierte que "algunos elementos de la presente crisis revelan de modo evidente su carácter moral". Tal es el caso de "la aplicación indiscriminada de los adelantos científicos y tecnológicos", aunque "el signo más profundo y grave de las implicaciones morales, inherentes a la cuestión ecológica, es la falta de respeto a la vida, como se ve en muchos comportamientos contaminantes". Esto se observa muy frecuentemente cuando se ponen por delante los beneficios económicos y se posterga la dignidad humana del trabajador, el bien de la persona individual y hasta de comunidades. "Es el respeto a la vida y, en primer lugar, a la dignidad de la persona humana la norma fundamental inspiradora de un sano progreso económico, industrial y científico"(Juan Pablo II, 1990, n³), concluye el romano pontífice.

Sin dejar de lado la responsabilidad que cada nación tiene, Juan Pablo II advierte la necesidad de una acción a nivel internacional y propone que el "derecho a un ambiente seguro" se incluya en la Carta de los derechos del hombre "puesta al día"(Juan Pablo II, 1990, n 9).

Retomando la idea de que la crisis ecológica está ligada a una crisis moral del hombre, el Papa afirma que "la sociedad actual no hallará una solución al problema ecológico si no revisa seriamente su estilo de vida. En muchas partes del mundo esta misma sociedad se inclina al hedonismo y al consumismo, pero permanece indiferente a los daños que éstos causan"(Juan Pablo II, 1990, $\left.n^{\circ} 13\right)$.

En la encíclica Evangelium Vitae, Juan Pablo II vuelve a referirse a la cuestión ecológica y a la «ecología humana», recordando el llamado que Dios hizo al hombre a cultivar y custodiar la tierra en el presente y también en relación con la responsabilidad que le compete respecto de las futuras generaciones.

En 1999, en la Exhortación Apostólica Post Sinodal Ecclesia in America, el Papa subraya la importancia de que los creyentes intervengan en el cuidado del medio ambiente y llama a todos los hombres de buena voluntad a unirse y colaborar "con las instancias legislativas y de gobierno para conseguir una protección eficaz"(Juan Pablo II, 1999, n²5) del mismo.

Durante diez años, los llamados del Papa a toda la humanidad para que asuma el compromiso del cuidado del medio ambiente fueron constantes y ya en el comienzo del nuevo milenio incorpora el concepto de "ecología humana", 
que completa la mirada de la ecología física. En la audiencia general del 17 de enero de 2001, el santo Padre dice:

No está en juego sólo una ecología "física", atenta a tutelar el hábitat de los diversos seres vivos, sino también una ecología "humana", que haga más digna la existencia de las criaturas, protegiendo el bien radical de la vida en todas sus manifestaciones y preparando a las futuras generaciones un ambiente que se acerque más al proyecto del Creador (Juan Pablo II, 2001).

Vemos entonces de qué manera se va entrelazando cada vez más la ecología con el auténtico desarrollo humano, un desarrollo que no solo tiene que ver con mejores condiciones económicas -como lo entiende en gran medida el capitalismo- sino con el bien integral de la persona humana, bien que es a la vez físico y espiritual.

En esta línea hay que entender la advertencia que hace Benedicto XVI en su encíclica Caritas in veritate, cuando llama la atención sobre la situación social y asevera que en esta época muchas personas creen que han logrado todo gracias a ellas mismas, exclusivamente por sus propios méritos y que no le deben nada a nadie. Son personas que hacen hincapié en los derechos que les corresponden pero se olvidan de la responsabilidad que tienen respecto del desarrollo integral de sí mismos y de los demás seres humanos. El mismo Papa profundiza dicha línea argumental y explicita sus palabras al decir que:

Se aprecia con frecuencia una relación entre la reivindicación del derecho a lo superfluo, e incluso a la transgresión y al vicio, en las sociedades opulentas, y la carencia de comida, agua potable, instrucción básica o cuidados sanitarios elementales en ciertas regiones del mundo subdesarrollado y también en la periferia de las grandes ciudades. Dicha relación consiste en que los derechos individuales, desvinculados de un conjunto de deberes que les dé un sentido profundo, se desquician y dan lugar a una espiral de exigencias prácticamente ilimitada y carente de criterios(Benedicto XVI, 2009, $n^{\circ} 43$ ).

Evidentemente, hay un contexto de inequidad, a partir de la exaltación de lo individual sin importar los perjuicios que eso puede acarrear a los demás, 


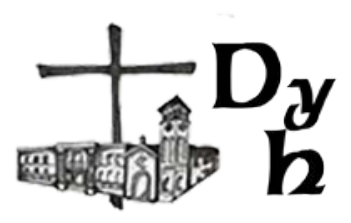

perjuicios que ponen ciertamente en riesgo la propia vida y la vida humana en general.

En la misma Caritas in veritate, Benedicto XVI afirma que "la naturaleza es expresión de un proyecto de amor y de verdad. Ella nos precede y nos ha sido dada por Dios como ámbito de vida"(Benedicto XVI, 2009, n48). La naturaleza remite al Creador y es una muestra de su amor hacia todos nosotros. Está puesta a nuestra disposición "como un don del Creador que ha diseñado sus estructuras intrínsecas para que el hombre descubra las orientaciones que se deben seguir para guardarla y cultivarla"(Benedicto XVI, 2009, n48). Aunque aclara inmediatamente que "es contrario al verdadero desarrollo considerar la naturaleza como más importante que la persona humana misma"(Benedicto XVI, 2009, $n^{\circ} 48$ ). Exceso en el que han caído algunos ecologistas, que concentraron su atención en la defensa del planeta, de los bosques o de las ballenas y no han sido igual de solícitos en la salvaguarda de los derechos de los seres humanos más indefensos.

\section{Francisco y la Laudato si'}

Al final de este recorrido, encontramos al Papa Francisco con su primera encíclica: Laudato si'o El cuidado de la casa común, en la que propone que "nos detengamos ahora a pensar en los distintos aspectos de una ecología integral, que incorpore claramente las dimensiones humanas y sociales"(Francisco, 2015, $\left.n^{\circ} 137\right)$.

En el número 95, el Papa afirma que "el medio ambiente es un bien colectivo, patrimonio de toda la humanidad y responsabilidad de todos"(Francisco, 2015, $\mathrm{n}^{\circ}$ 95), con lo cual queda clara la importancia de su conservación para lograr el bien común. Pero el llamado no termina allí ya que, agrega que "quien se apropia algo es sólo para administrarlo en bien de todos. Si no lo hacemos, cargamos sobre la conciencia el peso de negar la existencia de los otros"(Francisco, 2015, n95).

En el mismo párrafo, Francisco cita un documento de los Obispos de Nueva Zelanda quienes se cuestionan acerca del significado del quinto mandamiento cuando "un veinte por ciento de la población mundial consume recursos en tal medida que roba a las naciones pobres y a las futuras 
generaciones lo que necesitan para sobrevivir"(Francisco, 2015, n 95); (New Zealand Catholic Bishops Conference, 2006).

Por esa razón, es clave comprender que el deterioro cada vez mayor del medio ambiente, si bien repercute sobre toda la humanidad, impacta de manera más brutal sobre aquellos que viven en condiciones de pobreza. De allí la necesidad imperiosa de integrar la ecología con la justicia. Este es el motivo por el que la ecología, el cuidado de la casa común, se convierte en una auténtica cuestión social. Al respecto, en la carta encíclica se lee que "hoy no podemos dejar de reconocer que un verdadero planteo ecológico se convierte siempre en un planteo social, que debe integrar la justicia en las discusiones sobre el ambiente, para escuchar tanto el clamor de la tierra como el clamor de los pobres"(Francisco, 2015, $\mathrm{n}^{\circ}$ 49) porque "la degradación ambiental y la degradación humana y ética están íntimamente unidas"(Francisco, 2015, n²56).

El llamado a la reflexión se torna insistente debido a la necesidad de un cambio profundo en el modo de comportamiento de los seres humanos. Así el Papa enfatiza que "no podremos afrontar adecuadamente la degradación ambiental si no prestamos atención a causas que tienen que ver con la degradación humana y social"(Francisco, 2015, n 48). Y qué peor degradación puede existir que el egoísmo que anida en el corazón de quienes lo quieren todo para sí y condenan a muchos a vivir en la miseria. La degradación del planeta, que corra peligro y con él todos los que lo habitamos, no puede proceder sino de aquella degradación moral previa.

\section{Referencias}

Benedicto XVI. (2009). Caritas in veritate. Recuperado el 3 de marzo de 2019, de http://w2.vatican.va/content/benedict-xvi/es/encyclicals/documents/hf_benxvi_enc_20090629_caritas-in-veritate.html

Concilio Vaticano II. (1965). Constitución Gaudium et Spes. Recuperado el 3 de marzo de 2019, de http://www.vatican.va/archive/hist_councils/ii_vatican_council/documents/vatii_const_19641121_lumen-gentium_sp.html

Concilio Vaticano II. (1964). Constitución Lumen Gentium. Recuperado el 3 de marzo de 2019, de http://www.vatican.va/archive/hist_councils/ii_vatican_council/documents/vatii_const_19641121_lumen-gentium_sp.html 


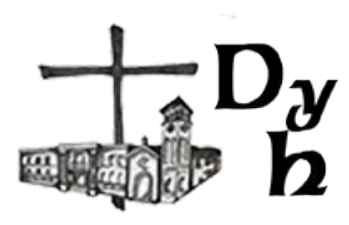

Francisco. (2015). Laudato si'. Recuperado el 9 de marzo de 2019, de http://w2.vatican.va/content/francesco/es/encyclicals/documents/papafrancesco_20150524_enciclica-laudato-si.html

Juan Pablo II. (17 de enero de 2001). Audiencia General. Recuperado el 7 de marzo de 2019, de http://w2.vatican.va/content/john-paul-ii/es/audiences/2001/documents/hf_jpii_aud_20010117.html

Juan Pablo II. (1991). Centesimus annus. Recuperado el 6 de marzo de 2019, de http://w2.vatican.va/content/john-paul-ii/es/encyclicals/documents/hf_jpii_enc_01051991_centesimus-annus.html

Juan Pablo II. (1999). Ecclesia in America. Recuperado el 7 de marzo de 2019, de http://w2.vatican.va/content/john-paul-ii/es/apost_exhortations/documents/hf_jpii_exh_22011999_ecclesia-in-america.html

Juan Pablo II. (1995). Evangelium vitae. Recuperado el 6 de marzo de 2019, de http://w2.vatican.va/content/john-paul-ii/es/encyclicals/documents/hf_jpii_enc_25031995_evangelium-vitae.html

Juan Pablo II. (1990). Mensaje para la celebración de la Jornada Mundial de la Paz. Recuperado el 6 de marzo de 2019, de http://w2.vatican.va/content/john-paulii/es/messages/peace/documents/hf_jp-ii_mes_19891208_xxiii-world-day-for-peace.html Juan Pablo II. (1979). Redemptor Hominis. Recuperado el 5 de marzo de 2019, de http://w2.vatican.va/content/john-paul-ii/es/encyclicals/documents/hf_jpii_enc_04031979_redemptor-hominis.html

Juan Pablo II. (1987). Sollicitudo rei Socialis. Recuperado el 6 de marzo de 2019, de http://w2.vatican.va/content/john-paul-ii/es/encyclicals/documents/hf_jpii_enc_30121987_sollicitudo-rei-socialis.html

Juan XXIII. (1961). Mater et Magistra. Recuperado el 3 de marzo de 2019, de http://w2.vatican.va/content/john-xxiii/es/encyclicals/documents/hf_jxxiii_enc_15051961_mater.html

Levoratti-Truso, P. (1999). Génesis. En S. Pablo (Ed.), El Libro del Pueblo de Dios, La Biblia. San Pablo.

New Zealand Catholic Bishops Conference. (1 de septiembre de 2006). Statement on Environmental Issues. Recuperado el 9 de marzo de 2019, de https://www.catholic.org.nz/about-us/bishops-statements/statement-on-environmentalissues/

Pablo VI. (16 de noviembre de 1970). Discurso en el $25^{\circ}$ aniversario de la FAO. Recuperado el 3 de marzo de 2019, de http://w2.vatican.va/content/paulvi/es/speeches/1970/documents/hf_p-vi_spe_19701116_xxv-istituzione-fao.html 


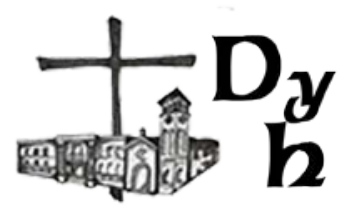

Pablo VI. (1 de junio de 1972). Mensaje a la Conferencia de las Naciones Unidas sobre el medio ambiente. Recuperado el 4 de marzo de 2019, de http://w2.vatican.va/content/paulvi/es/messages/pont-messages/documents/hf_p-vi_mess_19720605_conferenzaambiente.html

Pablo VI. (1971). Octogesima adveniens. Recuperado el 3 de marzo de 2019, de http://w2.vatican.va/content/paul-vi/es/apost_letters/documents/hf_pvi_apl_19710514_octogesima-adveniens.html 